Article

\title{
Relationship between Urban New Business Indexes and the Business Environment of Chinese Cities: A Study Based on Entropy-TOPSIS and a Gaussian Process Regression Model
}

\author{
Yishao Shi * (1D and Danxuan Liu \\ College of Surveying and Geo-Informatics, Tongji University, Shanghai 200092, China; liudanxuan@tongji.edu.cn \\ * Correspondence: shiyishao@tongji.edu.cn
}

Received: 25 November 2020; Accepted: 11 December 2020; Published: 13 December 2020

check for updates

\begin{abstract}
The interactive development of economic globalization, informatization, marketization, and urbanization has reshaped the urban commercial landscape and society, and poses new requirements for the business environment. New commerce forms that are based on information technology and electronic payment and integrate online and offline forms are growing rapidly in China. However, the relationship between new commerce forms and the business environment has not received sufficient academic attention. Using 29 major cities in China, this paper constructs a new business index system consisting of the following six sub-indexes: the characteristic hotels index, the Starbucks index, the Freshhema index, the concept bookstores index, the smart convenience stores index, and the healthcare and medical examination index. The entropy coupled with the Technique for Order Preference by Similarity to an Ideal Solution (TOPSIS) method was used for quantitative evaluation of urban new business vitality. We found that the Freshhema index and smart convenient store index are the two most important evaluation factors. The relationship between the new business index and the business environment was examined through multiple linear regression (MLR) and Gaussian process regression (GPR) analysis. We found that the MLR is not a valid model, and instead, the nonlinear GPR model has good explanatory power for this relationship. The results show that human capital has a more important effect than the economic development level on business vitality. The rise and development of new commercial forms depend on the innovation and optimization of the business environment.
\end{abstract}

Keywords: urban new business indexes; vitality evaluation; business environment; Entropy-TOPSIS method; Gaussian process regression; China

\section{Introduction}

Commercial space is the core area of a city's economic flow (e.g., population flow, goods flow, capital flow, technology flow, information flow) [1,2]. It is also the most attractive, vibrant, and competitive area. To a large extent, the life of the city derives from the commodity exchange that occurs to satisfy the demand for centralized space. As a highly composite area of urban activities and needs, commercial space develops and evolves through the agglomeration and diffusion of markets and market components. Urban commercial space in the modern sense is, in fact, a business circle or commercial cluster formed by a combination of attractive and impressive commercial forms. In particular, since the beginning of the 21st century, the interactive development of economic globalization, informatization, marketization, and urbanization has promoted the network connection of global resources, production, services, and consumption. The construction of a global supply chain has formed a new urban commercial landscape and given rise to a new commercial civilization [3-9]. 
All types of commercial subjects have emerged, and commercial forms and commercial models change with each passing day. At the same time, market competition is becoming increasingly fierce, and new requirements are emerging for the business environment. In the urban commercial space, permanence and change coexist, and the winner and the loser live together in their competition. Similarly, vitality and crisis coexist.

Commercial space has always been a focus of urban geography, urban planning, and urban economics. Particularly in the 21st century, traditional business models and lifestyles have been substantially affected by the drive towards globalization, the advance of information and communications technology, and the rapid development of intelligent and networked business. New commercial forms continue to emerge, providing new spaces in which to experience commercial shopping and leisure consumption for urban residents and demonstrating the new vitality brought by the new commercial forms to the city. This new commercial space has gradually become a topic of academic research.

One focus of such research is the location, type, scale, form, structure, and formative mechanism of new commercial spaces or new retail formats, such as malls, department stores, hypermarkets, supermarkets, convenience stores, discounters, and brand stores in developed countries $[10,11]$ and developing countries [1,2,12-17].

A second research focus is the impact of new urban commercial space development. Spilková and Sefrna [18] investigated the impact of new retail development on land use changes and the loss of quality of agricultural land. Wang [19] examined the impact of the changing external environment, particularly the shift in government policies, on the structure of retail formats in Beijing. Rotem-Mindali [20] applied ecological methods to analyze the impact of the spatial location of retail centers on city livability. Omer and Goldblatt [21] analyzed the association between spatial patterns of retail activity and the street network structure in new Israeli towns and traditional cities using space syntax. Their aim was to illustrate the influence of urban growth and planning approaches on the formation of retail activity and its interaction with the spatial configuration of street networks. Reinartz et al. [22] examined the impact of digital transformation on the retail value chain.

A third research focus is spatial resilience and sustainable development strategies for urban commercial spaces. Kärrholm et al. [23] identified the interdependence of three different types of Swedish retail locations from the perspective of spatial resilience. Erkip et al. [24] examined various retailer strategies and their impacts on urban space in a dynamic globalization environment in Turkey.

Since the beginning of the 21st century, the rapid development of computer science and information technology has become one of the main driving factors for global economic growth. Digital payment methods that are more convenient than traditional offline payment have also become mainstream payment methods. This article defines the new commerce form as a commerce form that is based on information technology and electronic payment to provide online and offline characteristics and personalized services. As of March 2020, the number of online payment users in China reached 768 million [25]. Due to changes in payment methods, consumption patterns in China have gradually been digitalized. In 2020, due to the impact of the COVID-19, the business volume of new retail formats in China grew rapidly. In the first quarter of 2020, the retail sales of new retail enterprises in Beijing increased by more than $70 \%$ year on year [26]. Freshhema is a new retail brand in mainland China that mainly uses electronic payment and integrates online and offline forms. In March 2020, Freshhema will start six new stores [27]. In September 2018, Starbucks' online food ordering service, Starbucks Delivery, was launched [28]. Users only need to place an order on a mobile phone to enjoy the delivery service. According to Starbucks China's official website, as of October 2020, Starbucks Delivery has covered 27 provincial administrative regions in China. New business formats have become an important part of Chinese business, and the new business patterns of Chinese cities have also shown their research value. The evaluation of new business vitality and its influencing factors are the focus of this article.

The last 30 years have seen the fastest pace of urbanization in the world. On the one hand, with the introduction of various new urban concepts, the study of relevant city indexes has attracted much 
attention, such as the Eco-City Index [29-31], Green City Index [32-34], Livable Cities Index [35,36], Compact City Index [37,38], Smart City Index [39], Resilient City Index [23,40], Innovative City Index [41,42], Global City Index [43,44], etc. For example, Jin [45] used a factor analysis method to evaluate the economic vitality of 50 cities in China from aspects of economy and its growth, number and income of enterprises, income of residents, financial and social security, foreign trade and capital, level of technology and education, and environment. He concluded that urban benefits and production are the main factors of the economic vitality. On the other hand, with the cyclical development of prosperity and the decline of cities, the Sustainable City Development Index [39,46] and Urban Competitiveness Index [47] have been widely paid attention to. For instance, Wang et al. [48] evaluated the urban innovation competitiveness based on five categories of indicators, i.e., innovation basic competitiveness, innovation environment competitiveness, innovation input competitiveness, innovation output competitiveness, and innovation and sustainable development competitiveness. However, in existing studies of various city indices, the urban new commercial index has not attracted enough attention. By studying this new business index, the purpose of this article is to address the following questions: (1) How can one quantitatively measure the vitality of a new commercial space? What are the advantages and disadvantages of each city in the development of new business forms? (2) What is the relationship between the vitality of a new business space and the business environment? What factors have more important effects on a city's new commercial vitality? (3) How can one enhance the vitality of a new business space and reshape its characteristics by optimizing the business environment? The business environment is the soil for the survival and development of enterprises. Optimizing the business environment will support the growth of enterprises, promote economic development, and improve the level of cities [49-53]. According to the World Bank's “Doing Business 2020", China, as the world's second-largest economy, ranks 31st among 190 economies in the ease of doing business. China's business environment still has much space for improvement. To this end, we propose the following three hypotheses: (1) Hypothesis I: The new business vitality is highly correlated with the business environment factors. (2) Hypothesis II: The human capital has a more important effect than economic development level on business vitality. (3) Hypothesis III: Cities with higher GDP have a higher urban vitality index.

\section{Methodology}

\subsection{Analysis Steps}

Figure 1 describes the analysis steps of this study. The analysis methods mentioned in this figure will be explained in detail below.

\subsection{Entropy-TOPSIS}

The Technique for Order Preference by Similarity to an Ideal Solution (TOPSIS) is a multiple-criteria decision-making (MCDM) method proposed by Hwang and Yoon [54]. TOPSIS provides reliable decision-making in multiple fields, such as business and marketing management [55,56], energy management [57,58], land use [59], and air quality [60]. The weighting method includes a subjective weighting method and an objective weighting method. Subjective weighting methods, like the Delphi method, direct rating, and simple multi-attribute rating techniques, etc., are affected by the subjective views of researchers. As an objective weighting method, the entropy method completely relies on the calculation of original data and can provide more accurate weights than the subjective method. TOPSIS makes full use of attribute information and does not require attribute preferences to be independent [61]. TOPSIS does not have strict restrictions on the number of indicators, sample size, or data distribution, and can provide reliable evaluation results through simple calculations [59]. For some complex MCDM methods, the sample should be large enough and the calculation process is cumbersome, which is not suitable for the small sample case of this research. Therefore, this article 
chose the Entropy-TOPSIS method from a variety of MCDM methods to evaluate the new business vitality of 29 Chinese cities.

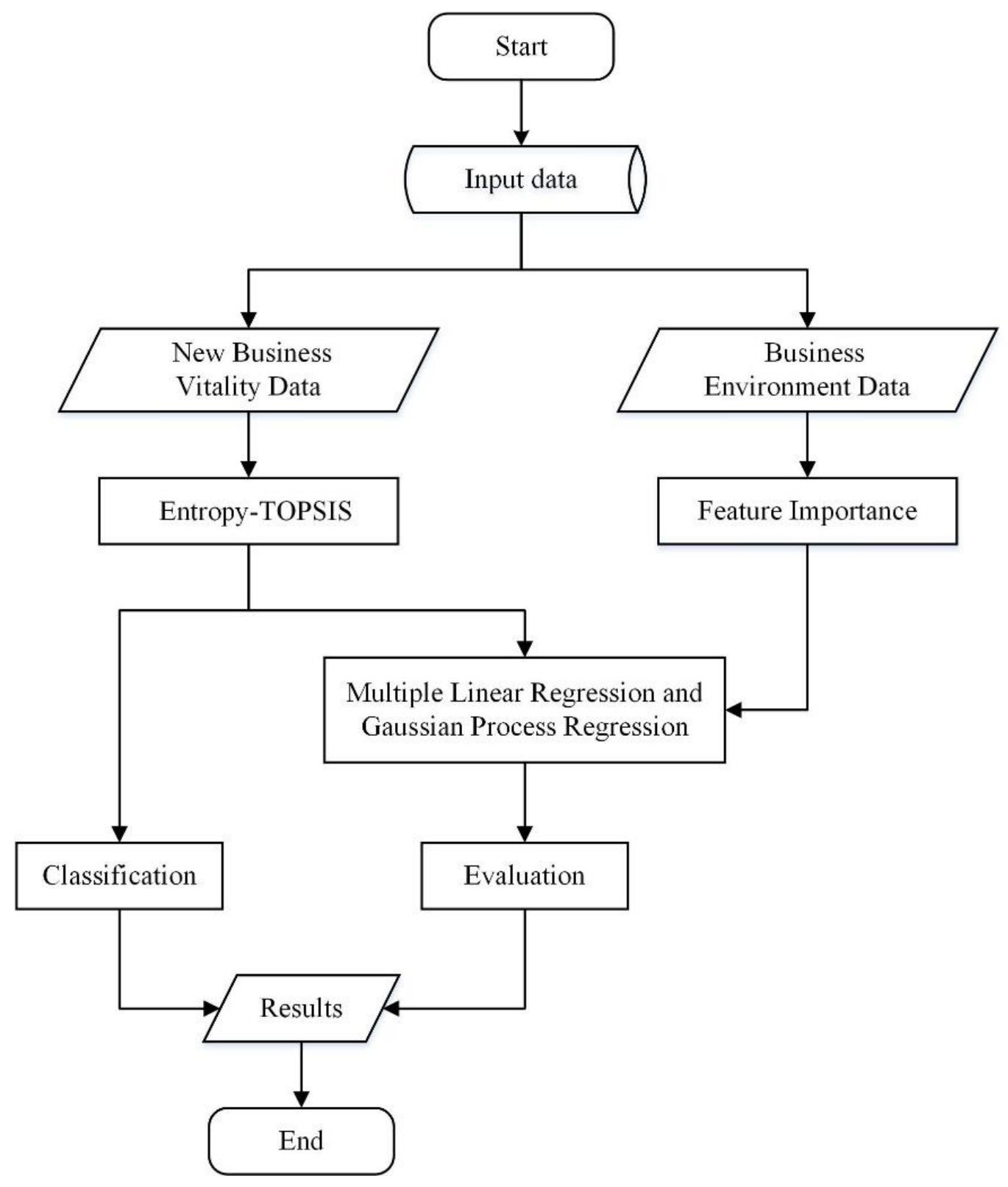

Figure 1. Analysis steps.

2.2.1. Calculating the Entropy Weight of Each Index

Step 1. Assuming $\mathrm{m}$ evaluation objects and $n$ evaluation indexes, the decision matrix $D$ is constructed as follows:

$$
D=\left(x_{i j}\right)_{m \times n} ; i=1,2, \ldots, m ; j=1,2, \ldots, n
$$

Step 2. Since the dimensions of different evaluation indexes are different, it is necessary to standardize the decision matrix $D$ to obtain the dimensionless decision matrix $Y=\left(y_{i j}\right)_{m \times n}$ :

$$
y_{i j}=\frac{x_{i j}}{\sqrt{\sum_{k=1}^{m}\left(x_{k j}\right)^{2}}} ; i=1,2, \ldots, m ; j=1,2, \ldots, n
$$


Step 3. Calculate the entropy value $E_{j}$ of the Jth evaluation index according to the definition of entropy in information theory:

$$
E_{j}=-\frac{1}{\ln (m)} \sum_{i=1}^{m} P_{i j} \ln \left(P_{i j}\right) ; j=1,2, \ldots, n
$$

where $P_{i j}=\frac{y_{i j}}{\sum_{k=1}^{m} y_{k j}} ; i=1,2, \ldots, m ; j=1,2, \ldots, n$; if $P_{i j}=0$, take $0 \ln 0=0[59,62]$.

Step 4. Calculate the entropy weight of the Jth evaluation index $w_{j}$ :

$$
w_{j}=\frac{\left(1-E_{j}\right)}{\sum_{k=1}^{n}\left(1-E_{k}\right)} ; j=1,2, \ldots, n
$$

\subsubsection{TOPSIS Method for Comprehensive Evaluation}

Step 1. Calculate the weighted normalized matrix $Z=\left(z_{i j}\right)_{m \times n}$ :

$$
z_{i j}=w_{j} y_{i j}
$$

where $y_{i j}$ is calculated according to Formula (2), and $w_{j}$ is calculated according to Formula (4).

Step 2. Determine positive ideal solution $Z^{+}$and the negative ideal solution $Z^{-}$

$$
\begin{aligned}
& Z^{+}=\left(z_{1}^{+}, z_{2}^{+}, \ldots, z_{n}^{+}\right) \\
& Z^{-}=\left(z_{1}^{-}, z_{2}^{-}, \ldots, z_{n}^{-}\right)
\end{aligned}
$$

where $z_{j}^{+}=\max _{1 \leq i \leq m} z_{i j}, z_{j}^{-}=\min _{1 \leq i \leq m} z_{i j} ; j=1,2, \ldots, n$.

Step 3. The distance between each evaluation object, the positive ideal solution, and the negative ideal solution is calculated as $d_{i}^{+}$and $d_{i}^{-}$:

$$
\begin{aligned}
& d_{i}^{+}=\sqrt{\sum_{j=1}^{n}\left(z_{i j}-z_{j}^{+}\right)^{2}} ; i=1,2, \ldots, m \\
& d_{i}^{-}=\sqrt{\sum_{j=1}^{n}\left(z_{i j}-z_{j}^{-}\right)^{2}} ; i=1,2, \ldots, m
\end{aligned}
$$

Step 4. Calculate the proximity between each evaluation object and positive ideal solution $c_{i}$ :

$$
c_{i}=\frac{d_{i}^{-}}{d_{i}^{+}+d_{i}^{-}} ; i=1,2, \ldots, m
$$

where $0 \leq c_{i} \leq 1$. The closer that $C_{i}$ is to 1 , the closer the evaluation object is to the optimal level. The closer that $c_{i}$ is to 0 , the closer the evaluation object is to the lowest level.

Step 5 . The evaluation objects are ranked according to their proximity, whereby those with high proximity are better than those with low proximity.

\subsection{Classification}

The SPSS 24.0 software (IBM, New York, NY, USA) was used to perform hierarchical cluster analysis, with the proximity of each evaluation object to the positive ideal solution as the variable. Additionally, Ward's minimum variance method was used to measure the squared Euclidean distance. 


\subsection{Feature Importance}

This article uses the RReliefF algorithm to determine the importance of business environment variables. This algorithm was proposed by Robnik-Sikonja and Kononenko [63]. This algorithm uses $\mathrm{k}$ nearest neighbors to rank the importance of predictor variables, and each variable will get a weight, which is between -1 and 1 ; more important predictor variables will get larger weights [64]. We used the statistics and machine learning toolbox in MATLAB R2018a to calculate the feature importance.

\subsection{Multiple Linear Regression (MLR)}

Multiple linear regression analysis is a classic regression analysis method that is suitable for the linear relationship with one response variable and multiple predictor variables. The multiple linear regression equation is as follows:

$$
\hat{Y}=b_{0}+b_{1} X_{1}+b_{2} X_{2}+\ldots+b_{p} X_{p}
$$

where $\hat{Y}$ is response variable, $X_{1}$ through $X_{p}$ are $p$ distinct predictor variables, $b_{0}$ is a constant term, and $b_{1}$ through $b_{p}$ are the estimated regression coefficients.

We used the STATA 14.0 software (StataCorp LLC, College Station, TX, USA) for the multiple linear regression.

\subsection{Gaussian Process Regression (GPR)}

The Gaussian process (GP) is a machine learning method, which can be regarded as the Bayesian version of the support vector machine method. In geology, GP is called the Kriging method and is usually used for prediction. Gaussian process regression (GPR) is a non-parametric, kernel-based probability model [65]. The equation of the standard regression model is as follows:

$$
y_{n}=f\left(\mathbf{x}_{\mathrm{n}}\right)+\varepsilon_{n}, \varepsilon_{n} \sim N\left(0, \sigma^{2}\right) i=1,2, \cdots, n
$$

where $\mathbf{x}_{n}=\left[x_{n}^{1}, x_{n}^{2}, \cdots, x_{n}^{P}\right], \varepsilon_{n}$ is the error term and $\sigma^{2}$ is the error variance.

In multiple linear regression, $f(\mathbf{x})$ is a linear parameter model. In Gaussian process regression, $\mathrm{f}(\mathrm{x})$ is a prior function of the Gaussian process with zero mean, which is $f(\mathbf{x}) \sim G P\left(0, k_{\theta}\left(\mathbf{x}, \mathbf{x}^{\prime}\right)\right)$, where $k_{\theta}\left(\mathbf{x}, \mathbf{x}^{\prime}\right)$ is the covariance function. $\varepsilon_{n}$ has a Gaussian prior. Therefore, choosing a suitable kernel is very important for GPR. The most widely used kernel is the squared exponential covariance function. The squared exponential covariance function corresponds to a Bayesian linear regression model with an infinite basis function, which is infinitely differentiable, leading to the process being infinitely mean-square differentiable [65-67]. The squared exponential kernel used in this study is as follows:

$$
k\left(x_{i}, x_{j} \mid \theta\right)=\sigma_{f}^{2} \exp \left[-\frac{1}{2} \frac{\left(x_{i}-x_{j}\right)^{T}\left(x_{i}-x_{j}\right)}{\sigma_{l}^{2}}\right]
$$

where $\sigma_{l}$ is the characteristic length scale, and $\sigma_{f}$ is the standard deviation. We used the statistics and machine learning toolbox in MATLAB R2018a for the Gaussian process regression.

\subsection{Evaluation}

This paper uses three statistical indicators to evaluate the goodness of fit for the multiple linear regression and Gaussian process regression. The three indicators are: (1) $R^{2}$, which indicates the proportion of the variance for a response variable that is explained by predictor variables in a regression model; (2) the sum of squares error (SSE); (3) CV (RMSE), which is the coefficient of variation (CV) of 
the root-mean squared error (RMSE), which is common in energy use models. The calculation methods of the three indicators are as follows:

$$
\begin{gathered}
R^{2}=1-\frac{\sum_{1=1}^{N}\left(y_{i}-\hat{y}\right)^{2}}{\sum_{i=1}^{N}\left(y_{i}-\bar{y}\right)^{2}} \\
S S E=\sum_{i=1}^{N}\left(y_{i}-\hat{y}\right)^{2} \\
C V(R M S E)=\frac{\sqrt{\sum_{i=1}^{N}\left(y_{i}-\hat{y}\right)^{2} / N}}{\bar{y}}
\end{gathered}
$$

where $y_{i}$ is the response variable, $\hat{y}$ is the predicted variable, and $\bar{y}$ is the mean of the response variables.

\section{Case Study}

\subsection{Data Collection}

\subsubsection{City New Business Form Index}

Based on 29 major cities in China (Beijing, Shanghai, Nanjing, Hangzhou, Ningbo, Hefei, Fuzhou, Xiamen, Nanchang, Jinan, Qingdao, Tianjin, Shijiazhuang, Taiyuan, Zhengzhou, Wuhan, Changsha, Guangzhou, Shenzhen, Nanning, Haikou, Chengdu, Chongqing, Guiyang, Kunming, Shenyang, Dalian, Harbin, and Xi'an), the vitality of China's new business forms was comprehensively evaluated. Six typical emerging business formats were selected: concept bookstores, smart convenience stores, characteristic hotels, fashionable beverage stores, fresh supermarkets, and healthcare institutions. Concept bookstores are bookstores that provide unique and personalized operation services while selling books $[68,69]$. Smart convenience stores are a new retail service based on intelligent technology [70]. Characteristic hotels are hotels that express a unique cultural idea and may provide a related characteristic consumption experience [71-73]. Fashionable beverage stores are shops with unique positioning that offer fashionable drinks that differ from traditional drinks (e.g., Starbucks coffee shops). "Fresh supermarkets" refer to a new retail format of "supermarket + catering + logistics distribution" (e.g., Freshhema) [74]. Healthcare institutions are medical institutions that provide medical examinations and other health management services. Data on major brand stores of these six typical emerging business formats in 29 cities are shown in Table 1.

According to the six types of emerging business formats, six new commercial indexes were constructed: the characteristic hotel index, Starbucks index, Freshhema index, concept bookstores index, smart convenience store index, and healthcare and medical examination index. All indexes are calculated based on ownership per million people (Table 2). This index system includes the degree of innovation (e.g., the Freshhema index), the degree of fashionableness (e.g., the characteristic hotel index, the concept bookstore index, and the healthcare and medical examination index), the degree of activity (e.g., the Starbucks index), and the degree of intelligence (e.g., the smart convenience store index) of the studied urban businesses. 
Table 1. Brands and data of six new commercial formats.

\begin{tabular}{|c|c|c|c|c|}
\hline Business Formats & Symbol & Brands & Data Sources & Year \\
\hline $\begin{array}{l}\text { Characteristic } \\
\text { hotels }\end{array}$ & $\mathrm{CH}$ & Atour Hotel, XanaHotelle, James Joyce Coffetel & $\begin{array}{l}\text { Official brand } \\
\text { websites }\end{array}$ & \multirow{6}{*}{2018} \\
\hline $\begin{array}{c}\text { Fashionable } \\
\text { beverage shops }\end{array}$ & SB & Starbucks & www.dianping.com & \\
\hline $\begin{array}{l}\text { Fresh-food-focused } \\
\text { supermarkets }\end{array}$ & $\mathrm{FH}$ & Freshhema & $\begin{array}{l}\text { Official brand } \\
\text { websites }\end{array}$ & \\
\hline Concept bookstores & $\mathrm{CB}$ & $\begin{array}{l}\text { Sisyphe, Zhongshuge, Yanjiyou, Belencre, } \\
\text { Momibook, Fangsuo, Popular Bookmall }\end{array}$ & $\begin{array}{l}\text { Official brand } \\
\text { websites and } \\
\text { www.dianping.com }\end{array}$ & \\
\hline $\begin{array}{l}\text { Smart convenient } \\
\text { stores }\end{array}$ & SC & $\begin{array}{l}\text { Jingdong X Unmanned Supermarket, F5 Future } \\
\text { Store, Eatbox, Bingobox, Oushang Unmanned } \\
\text { Supermarket, Zhizai, Imxiaomai, Bintang, } \\
\text { Buy-Fresh Go, Dd Fan, Weplay, Tao Café, Icygo, } \\
\text { Douce E-Self, Zhongdamen, Gobox, Higa-Box, } \\
\text { A-Bianli, Zhu, New Dream Life, Wow!, Jian24, } \\
\text { Fu-Shop, Fuligo, I-Store, Easygo, E+, Cloud-Go }\end{array}$ & www.dianping.com & \\
\hline $\begin{array}{l}\text { Healthcare and } \\
\text { physical } \\
\text { examination } \\
\text { institutions }\end{array}$ & $\mathrm{HC}$ & $\begin{array}{l}\text { Rich-Healthcare, Ciming, Ikang, Health-100, } \\
\text { Remehealth, Ipuhui, Minzhong-Healthcare }\end{array}$ & www.dianping.com & \\
\hline
\end{tabular}

Table 2. Original data and ranks of the new commercial format indexes of 29 cities in China (unit: per million people).

\begin{tabular}{|c|c|c|c|c|c|c|c|c|c|c|c|c|}
\hline \multirow{2}{*}{ City } & \multicolumn{2}{|c|}{$\mathrm{CH}$} & \multicolumn{2}{|c|}{ SB } & \multicolumn{2}{|c|}{ FH } & \multicolumn{2}{|c|}{ CB } & \multicolumn{2}{|c|}{ SC } & \multicolumn{2}{|c|}{ HC } \\
\hline & Index & Rank & Index & Rank & Index & Rank & Index & Rank & Index & Rank & Index & Rank \\
\hline Beijing & 1.161 & 11 & 15.690 & 4 & 0.603 & 2 & 1.346 & 8 & 1.114 & 5 & 2.646 & 3 \\
\hline Shanghai & 1.114 & 12 & 30.613 & 1 & 0.825 & 1 & 1.527 & 5 & 0.289 & 18 & 1.857 & 10 \\
\hline Nanjing & 1.422 & 6 & 13.158 & 7 & 0.356 & 8 & 1.778 & 4 & 0.356 & 14 & 1.304 & 20 \\
\hline Hangzhou & 2.217 & 4 & 24.971 & 3 & 0.467 & 6 & 1.867 & 3 & 0.583 & 11 & 1.517 & 16 \\
\hline Ningbo & 0.692 & 22 & 25.363 & 2 & 0.461 & 7 & 0.692 & 19 & 0.922 & 8 & 1.845 & 11 \\
\hline Hefei & 4.062 & 1 & 6.347 & 15 & 0 & 13 & 1.523 & 6 & 0 & 24 & 2.539 & 4 \\
\hline Fuzhou & 1.269 & 9 & 6.853 & 12 & 0.508 & 5 & 1.269 & 9 & 0.254 & 21 & 0.508 & 28 \\
\hline Xiamen & 0.973 & 14 & 3.406 & 26 & 0 & 13 & 0.973 & 12 & 0.973 & 6 & 0.973 & 24 \\
\hline Nanchang & 0.897 & 17 & 5.679 & 18 & 0 & 13 & 0.598 & 21 & 0.299 & 16 & 1.793 & 13 \\
\hline Jinan & 1.113 & 13 & 4.132 & 23 & 0 & 13 & 0.159 & 29 & 0.318 & 15 & 1.271 & 21 \\
\hline Qingdao & 0.787 & 21 & 6.769 & 13 & 0 & 13 & 0.787 & 14 & 0.472 & 12 & 1.102 & 23 \\
\hline Tianjin & 0.898 & 16 & 5.899 & 17 & 0 & 13 & 0.385 & 24 & 0.256 & 20 & 1.411 & 18 \\
\hline Shijiazhuang & 1.399 & 7 & 1.799 & 29 & 0 & 13 & 0.200 & 28 & 0 & 24 & 0.800 & 26 \\
\hline Taiyuan & 0.829 & 20 & 4.7 & 21 & 0 & 13 & 0.276 & 26 & 0 & 24 & 1.935 & 7 \\
\hline Zhengzhou & 1.531 & 5 & 3.828 & 25 & 0 & 13 & 0.383 & 25 & 0.191 & 22 & 1.914 & 9 \\
\hline Wuhan & 0.632 & 24 & 9.385 & 9 & 0.271 & 11 & 0.722 & 17 & 0.271 & 19 & 1.263 & 22 \\
\hline Changsha & 0.937 & 15 & 7.499 & 11 & 0 & 13 & 0.703 & 18 & 0.937 & 7 & 2.109 & 5 \\
\hline Guangzhou & 0.872 & 19 & 10.869 & 8 & 0.201 & 12 & 0.268 & 27 & 2.013 & 3 & 1.476 & 17 \\
\hline Shenzhen & 0.691 & 23 & 13.434 & 6 & 0.307 & 10 & 1.151 & 11 & 0.384 & 13 & 1.842 & 12 \\
\hline Nanning & 0 & 28 & 4.075 & 24 & 0 & 13 & 0.453 & 22 & 0.679 & 10 & 1.358 & 19 \\
\hline Haikou & 0 & 28 & 5.212 & 20 & 0 & 13 & 0.434 & 23 & 2.172 & 1 & 1.737 & 15 \\
\hline Chengdu & 2.812 & 3 & 13.771 & 5 & 0.582 & 3 & 1.94 & 2 & 0.873 & 9 & 3.297 & 1 \\
\hline Chongqing & 0.614 & 25 & 2.662 & 28 & 0 & 13 & 0.819 & 13 & 0.082 & 23 & 0.451 & 29 \\
\hline Guiyang & 1.162 & 10 & 4.648 & 22 & 0.581 & 4 & 2.324 & 1 & 0 & 24 & 1.743 & 14 \\
\hline Kunming & 0.457 & 26 & 5.945 & 16 & 0 & 13 & 0.686 & 20 & 0 & 24 & 0.915 & 25 \\
\hline Shenyang & 0.875 & 18 & 5.394 & 19 & 0 & 13 & 0.729 & 15 & 0.292 & 17 & 3.207 & 2 \\
\hline Dalian & 0.407 & 27 & 6.724 & 14 & 0 & 13 & 1.222 & 10 & 2.037 & 2 & 2.037 & 6 \\
\hline Harbin & 1.271 & 8 & 3.268 & 27 & 0 & 13 & 0.726 & 16 & 0 & 24 & 0.726 & 27 \\
\hline Xi'an & 3.154 & 2 & 7.547 & 10 & 0.338 & 9 & 1.352 & 7 & 1.239 & 4 & 1.915 & 8 \\
\hline
\end{tabular}




\subsubsection{Evaluation Index System for the Urban Business Environment}

The "macro business environment" refers to the important background environment of a country or region against which it conducts international exchanges and cooperation and participates in international competition. The micro business environment is the sum of the circumstances and conditions surrounding an enterprise from its inception and operation to its termination [75-78]. The "urban business environment" primarily refers to the comprehensive environment at the medium level, including the market environment, social service environment, business cost environment, soft environment, and ecological environment. The urban business environment embodies the soft power, competitiveness, and efficiency of an urban economy. Based on relevant academic research results $[79,80]$, this article selected 10 indicators to construct a city business environment evaluation index system. The indicators are as follows: hospital beds per ten thousand residents, per capita expenditure on science and technology, per capita gross domestic product (GDP), per capita total retail sales of consumer goods, green coverage ratio in built-up areas, annual number of good-air-quality days, the quality of the labor force, the average salary of urban employees, the ratio of house prices to incomes, and the annual number of tourists. The basic information of the 10 indicators is shown in Table 3 . Per capita GDP and per capita total retail sales of consumer goods are two representative indicators of the market environment, which determines the size of the enterprise profit space. Hospital beds per ten thousand residents and per capita expenditure on science and technology are two indicators used to represent the social service environment. The average salary of urban employees and the ratio of house prices to incomes are two typical indicators of the business cost environment. Two indicators (i.e., the quality of the labor force and the annual number of tourists) are used to represent the urban soft environment, which is the most important factor for enterprises when choosing investments. The quality of the labor force is measured by the number of workers in scientific research and technical services per ten thousand inhabitants. The green coverage ratio in built-up areas and the annual number of good-air-quality days are two representative indexes of the urban ecological environment.

Table 3. Description of the business environment indicators.

\begin{tabular}{cccc}
\hline Variables & Unit & Symbol & Year \\
\hline Hospital beds & per ten thousand people & HB & 2018 \\
Per capita expenditure on science and technology & yuan & EST & 2018 \\
Per capita gross domestic product & thousand yuan & GDP & 2018 \\
Per capita total retail sales of consumer goods & thousand yuan & TRS & 2018 \\
Green coverage ratio in built-up areas & $\%$ & GCR & 2018 \\
Annual number of good-air-quality days & day & GAQ & 2017 \\
Labor quality & persons/ten thousand people & LQ & 2018 \\
Average salary of urban employees & thousand yuan & AS & 2018 \\
House price to income ratio & - & HPI & 2018 \\
Annual number of tourists & million people & TN & 2018 \\
\hline
\end{tabular}

The data on the ten described indicators were obtained from the "Statistical Yearbook of Chinese Cities in 2019". In addition, the ratio of house prices to incomes was obtained from the website of the National Bureau of Statistics of China. The annual number of good-air-quality days was obtained from the "2018 China Statistical Yearbook on the Environment". The annual number of tourists was obtained from the corresponding city's statistical yearbook. The descriptions of business environment indicators are shown in Table 3 and the data of the indicators are shown in Table 4. 
Table 4. Evaluation indexes and data of China's urban business environment.

\begin{tabular}{|c|c|c|c|c|c|c|c|c|c|c|}
\hline City & HB & EST & GDP & TRS & GCR & GAQ & LQ & AS & HPI & TN \\
\hline Beijing & 3.978 & 1976.934 & 140.748 & 4.534 & 48.44 & 226 & 332.907 & 149.843 & 0.250 & 35.315 \\
\hline Shanghai & 53.226 & 1759.093 & 134.830 & 2.268 & 39.40 & 275 & 110.958 & 142.983 & 0.203 & 304.754 \\
\hline Nanjing & 58.614 & 954.743 & 151.969 & 69.136 & 45.10 & 267 & 93.579 & 111.071 & 0.177 & 112.060 \\
\hline Hangzhou & 80.239 & 1316.435 & 145.929 & 61.971 & 40.63 & 271 & 102.068 & 106.709 & 0.228 & 140.590 \\
\hline Ningbo & 57.694 & 1198.328 & 156.054 & 60.347 & 42.00 & 311 & 34.445 & 102.325 & 0.158 & 93.715 \\
\hline Hefei & 95.397 & 1994.034 & 133.685 & 59.101 & 43.37 & 224 & 110.729 & 89.022 & 0.147 & 92.787 \\
\hline Fuzhou & 61.541 & 363.129 & 121.281 & 87.430 & 44.93 & 349 & 83.099 & 83.175 & 0.173 & 55.223 \\
\hline Xiamen & 37.328 & 694.7 & 116. & 37.529 & 45.12 & 362 & 52.487 & 85. & 0.396 & 67.702 \\
\hline Nanchang & 73.048 & 715. & 118. & 54.062 & 44.80 & 300 & 74.049 & 82. & 0.100 & 83.011 \\
\hline Jinan & 72.754 & 331.316 & 115. & 66.613 & 40.49 & 181 & 68.180 & 91.651 & 0.133 & 66.185 \\
\hline Qingdao & 63.106 & 668.176 & 146.446 & 56.202 & 39.20 & 283 & 52.801 & 90.840 & 0.136 & 80.810 \\
\hline Tianjin & 38.687 & 677.800 & 120.606 & 35.477 & 38.03 & 209 & 69.249 & 103.931 & 0.153 & 191.46 \\
\hline Shijiazhuang & 65.589 & 179.699 & 68.314 & 37.028 & 41.16 & 151 & 74.858 & 75.114 & 0.138 & 76.477 \\
\hline Taiyuan & 95.294 & 47.631 & 99.704 & 43.005 & 44.67 & 176 & 116.528 & 80.825 & 0.134 & 56.881 \\
\hline Zhengzhou & 126.513 & 539. & 115 & 45.407 & 40.83 & 166 & 102.915 & 80. & 0.101 & 89.336 \\
\hline Wuhan & 73.788 & 1212. & 133. & 61.762 & 39.46 & 25 & 82.990 & 88. & 0.144 & 233.210 \\
\hline Changsha & 115.065 & 655.501 & 165.692 & 82.863 & 41.49 & 262 & 116.373 & 93.293 & 0.084 & 124.500 \\
\hline Guangzhou & 57.708 & 1098.102 & 153. & 62.104 & 45.13 & 294 & 96.745 & 111.839 & 0.193 & 185.479 \\
\hline Shenzhen & 33.446 & 4260.373 & 185.942 & 47.356 & 44.98 & 343 & 99.734 & 111.709 & 0.496 & 124.854 \\
\hline Nanning & 70.126 & 163.231 & 74.468 & 41.045 & 42.36 & 337 & 70.283 & 83.452 & 0.092 & 95.552 \\
\hline Haikou & 62.850 & 108.565 & 65.609 & 32.904 & 41.00 & 352 & 57.125 & 77.632 & 0.163 & 21.861 \\
\hline Chengdu & 80.285 & 549.997 & 119.287 & 27.939 & 41.33 & 235 & 164.607 & 88.011 & 0.111 & 200.280 \\
\hline Chongqing & 52.030 & 147.188 & 72.839 & 27.862 & & 277 & 32.666 & 81.764 & 0.100 & 450.861 \\
\hline Guiyang & 80.5 & 559. & & & & & 82.9 & & 0.107 & 10.918 \\
\hline Kunming & 99.943 & 352.725 & 94.410 & 55.585 & 41.93 & 360 & 113.432 & 80.253 & 0.138 & 101.136 \\
\hline Shenyang & 89.485 & 83.896 & 81.899 & 56.044 & 39.23 & 256 & 59.500 & 82.067 & 0.106 & 64.577 \\
\hline Dalian & 67.665 & 721.612 & 120.961 & 68.679 & 46.67 & 300 & 34.768 & 87.592 & 0.131 & 77.382 \\
\hline Harbin & 120.277 & 195.082 & 86.394 & 62.516 & 35.37 & 271 & 47.970 & 71.771 & 0.124 & 70.618 \\
\hline Xi'an & 68.225 & 33.431 & 90.282 & 52.118 & 38.75 & 180 & 142.831 & 87.125 & 0.115 & 150.126 \\
\hline
\end{tabular}

\subsection{Results}

\subsubsection{Evaluation Results Based on the Entropy-TOPSIS Method}

According to the original data (Table 2), the entropy weight of each index was calculated. As can be seen from Table 5, the largest entropy weight is that of the Freshhema index, which is about 0.422; the smart convenient store index has the next at about 0.236 , followed by the Starbucks index, the characteristic hotel index, and the concept bookstore index, while the entropy weight of healthcare and medical examination index is the smallest. The higher that the entropy weight is, the greater the per capita difference in the index value. Due to the high technical threshold and expensive operation costs, the development levels of Freshhema stores and smart convenience stores in different cities are obviously different. As improved models of coffee shops, ordinary hotels, and bookstores, Starbucks coffee shops, characteristic hotels and concept bookstores, respectively, have been expanded in various cities. There are relatively few differences among the healthcare and medical examination institutions in different cities. Additionally, the Freshhema and the smart convenience store indexes, which exhibit the largest differences in development level, have the largest weights in the comprehensive evaluation.

Table 5. Entropy weights of the six new commercial format indexes.

\begin{tabular}{ccccccc}
\hline & CH & SB & FH & CB & SC & HC \\
\hline Entropy weight $(w)$ & 0.109 & 0.112 & 0.422 & 0.081 & 0.236 & 0.040 \\
\hline
\end{tabular}

Table 6 shows the evaluation results of the new business vitality of 29 Chinese cities based on the Entropy-TOPSIS method, which could be divided into five categories (Table 7). In order to see 
the differences in the five categories more clearly, we select one city from each of the five categories to make comparisons with the positive and negative ideal solutions (Figure 2). Tables 2 and 6 reveal the single and comprehensive rankings of the six new business indexes of the 29 cities, respectively. The classification results also reveal the following.

Table 6. Evaluation results for the new commercial vitality of 29 Chinese cities based on the entropy and Technique for Order Preference by Similarity to an Ideal Solution (TOPSIS) evaluation method.

\begin{tabular}{cccccccccc}
\hline City & $\boldsymbol{d}_{\boldsymbol{i}}^{+}$ & $\boldsymbol{d}_{\boldsymbol{i}}^{-}$ & $\boldsymbol{c}_{\boldsymbol{i}}$ & Ranking & City & $\boldsymbol{d}_{\boldsymbol{i}}^{+}$ & $\boldsymbol{d}_{\boldsymbol{i}}^{-}$ & $\boldsymbol{c}_{\boldsymbol{i}}$ & Ranking \\
\hline Shanghai & 0.240 & 0.365 & 0.604 & 1 & Changsha & 0.396 & 0.119 & 0.231 & 16 \\
Chengdu & 0.198 & 0.296 & 0.599 & 2 & Xiamen & 0.402 & 0.118 & 0.227 & 17 \\
Beijing & 0.209 & 0.285 & 0.577 & 3 & Shenyang & 0.427 & 0.082 & 0.161 & 18 \\
Hangzhou & 0.237 & 0.260 & 0.524 & 4 & Nanning & 0.430 & 0.077 & 0.151 & 19 \\
Ningbo & 0.255 & 0.244 & 0.490 & 5 & Qingdao & 0.420 & 0.074 & 0.149 & 20 \\
Xi'an & 0.255 & 0.238 & 0.483 & 6 & Zhengzhou & 0.432 & 0.075 & 0.149 & 21 \\
Guiyang & 0.312 & 0.253 & 0.447 & 7 & Nanchang & 0.429 & 0.064 & 0.130 & 22 \\
Guangzhou & 0.314 & 0.236 & 0.430 & 8 & Jinan & 0.433 & 0.061 & 0.124 & 23 \\
Fuzhou & 0.304 & 0.212 & 0.411 & 9 & Harbin & 0.445 & 0.061 & 0.120 & 24 \\
Nanjing & 0.305 & 0.184 & 0.376 & 10 & Shijiazhuang & 0.451 & 0.059 & 0.116 & 25 \\
Dalian & 0.380 & 0.227 & 0.373 & 11 & Tianjin & 0.433 & 0.056 & 0.1150 & 26 \\
Haikou & 0.397 & 0.233 & 0.369 & 12 & Taiyuan & 0.450 & 0.050 & 0.099 & 27 \\
Shenzhen & 0.329 & 0.153 & 0.318 & 13 & Chongqing & 0.450 & 0.042 & 0.085 & 28 \\
Hefei & 0.415 & 0.189 & 0.313 & 14 & Kunming & 0.450 & 0.040 & 0.082 & 29 \\
Wuhan & 0.357 & 0.123 & 0.256 & 15 & & & & & \\
\hline
\end{tabular}

Table 7. Classification of 29 cities in China according to their new commercial vitality indexes.

\begin{tabular}{ccc}
\hline Class & Proportion & City \\
\hline Class I: high & $10.34 \%$ & Shanghai, Chengdu, Beijing \\
Class II: moderately high & $20.69 \%$ & Hangzhou, Ningbo, Xi'an, Guiyang, Guangzhou, Fuzhou \\
Class III: moderate & $17.25 \%$ & Nanjing, Dalian, Haikou, Shenzhen, Hefei \\
Class IV: moderately low & $10.34 \%$ & Wuhan, Changsha, Xiamen \\
Class V: low & $41.38 \%$ & Shenyang, Nanning Qingdao, Zhengzhou, Nanchang, Jinan, \\
& & Harbin, Shijiazhuang, Tianjin, Taiyuan, Chongqing, Kunming \\
\hline
\end{tabular}

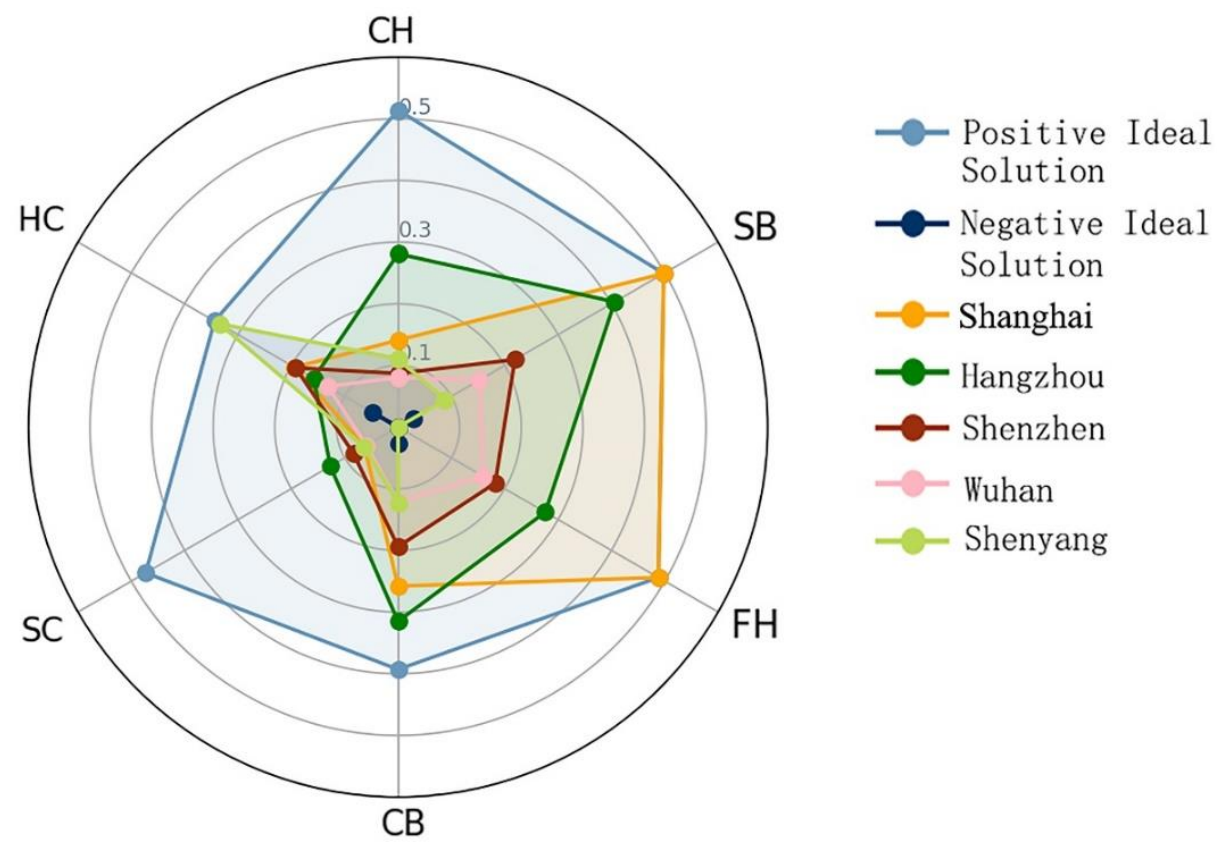

Figure 2. The six new business form indexes in five representative cities. 
(1) Shanghai, Chengdu, and Beijing have high indexes of new business vitality. Shanghai's Freshhema index and Starbucks index both rank first, making Shanghai the only city among the 29 studied cities with two indexes that rank first. However, Shanghai's smart convenience store index is its weakest index. Chengdu and Beijing each rank relatively high, with five and four indexes among the top five.

(2) Hangzhou, Ningbo, Xi'an, Guiyang, Guangzhou, and Fuzhou have relatively higher new business vitality indexes. The indexes of Hangzhou are relatively balanced, with three indexes ranking among the top five. Ningbo, Guiyang, and Fuzhou all exhibit shortcomings. Ningbo's Starbucks index is second only to that of Shanghai, and its Freshhema index ranks seventh. However, Ningbo's concept bookstore index and characteristic hotel index rank 19th and 22nd. Guiyang's concept bookstore index and Freshhema index rank first and fourth, respectively. However, its Starbucks index and smart convenience store index both rank below 20. Fuzhou's Freshhema index ranks fifth, while its smart convenient store index and health-care and medical institution index rank 21st and 28th. In the Pearl River Delta, Guangzhou is the most dynamic city for new business.

(3) Five cities (i.e., Nanjing, Dalian, Haikou, Shenzhen, and Hefei) scored in the middle. Among these cities, Nanjing and Shenzhen do not rank high in the Freshhema index and the smart convenience store index. However, each index in these cities is in the middle or above, with five indexes ranking in the top 14. Dalian and Haikou have not introduced Freshhema stores yet. However, their smart convenience store indexes ranked second and first, respectively, with five and two other indexes, respectively, ranking among the top 14.

(4) Three cities (i.e., Wuhan, Changsha, and Xiamen) had lower indexes of new business vitality. Changsha and Xiamen have not introduced Freshhema shops. The smart convenience store indexes of Wuhan do not enter the top 10. In addition, each city has at least two indexes that rank below 14.

(5) The cities of Shenyang, Nanning Qingdao, Zhengzhou, Nanchang, Jinan, Harbin, Shijiazhuang, Tianjin, Taiyuan, Chongqing, and Kunming had the lowest new business vitality index. In particular, their Freshhema, smart convenience store, and Starbucks indexes were mostly at low levels.

\subsubsection{Feature Importance}

We used the RReliefF algorithm to rank the importance of 10 business environment variables based on 10 nearest neighbors, and the results are shown in Table 8. According to the rankings, the most important variables are labor quality, annual numbers of tourists, and per capita total retail sales of consumer goods, and the least important variables are per capita gross domestic product, annual number of good-air-quality days, and green coverage ratio in built-up areas. From the results, we found that the human capital has a more important effect than economic development level on business vitality, which validates our Hypothesis II.

Table 8. Feature importance of the business environment variables.

\begin{tabular}{ccccccccccc}
\hline & HB & EST & GDP & TRS & GCR & GAQ & LQ & AS & HPI & TN \\
\hline Rank & 7 & 6 & 10 & 3 & 8 & 9 & 1 & 4 & 5 & 2 \\
Weights & -0.008 & 0.001 & -0.021 & 0.019 & -0.010 & -0.014 & 0.041 & 0.017 & 0.002 & 0.039 \\
\hline
\end{tabular}

\subsubsection{MLR and GPR Analysis Results}

Table 9 shows the results of MLR. Based on the p-values, the coefficients of all variables are not statistically significant and the MLR model is not suitable for this issue. 
Table 9. Result of the multiple linear regression (MLR) model.

\begin{tabular}{ccc}
\hline Variable & Coefficient & $p$-Value \\
\hline HB & $-1.736 \times 10^{-3}$ & 0.437 \\
EST & $9.240 \times 10^{-6}$ & 0.900 \\
GDP & $7.726 \times 10^{-4}$ & 0.687 \\
TRS & $-2.174 \times 10^{-4}$ & 0.941 \\
GCR & $-8.698 \times 10^{-3}$ & 0.532 \\
GAQ & $7.926 \times 10^{-4}$ & 0.180 \\
LQ & $1.299 \times 10^{-3}$ & 0.166 \\
AS & $3.807 \times 10^{-3}$ & 0.285 \\
HPI & $-5.180 \times 10^{-1}$ & 0.422 \\
TN & $-3.432 \times 10^{-4}$ & 0.419 \\
\hline
\end{tabular}

According to the theory of RReliefF algorithm, features with negative weights are not important for the response variable. So, we selected six business environment variables, i.e., per capita expenditure on science and technology (EST), per capita total retail sales of consumer goods (TRS), labor quality (LQ), average salary of urban employees (AS), house price to income ratio (HPI), and annual number of tourists (TN), as the predictor variables in the GPR model. We used the same data for the training and testing data of the GPR. The quantile-quantile plot of the residuals of the GPR (Figure 3) and the Jarque-Bera test ( $p$-value: $0.61>0.05$ ) indicate that the residuals conform to the normal distribution. From the comparison between the actual values and predicted values of the new business vitality indexes in the GPR model (Figure 4), we found that the GPR model fits well.

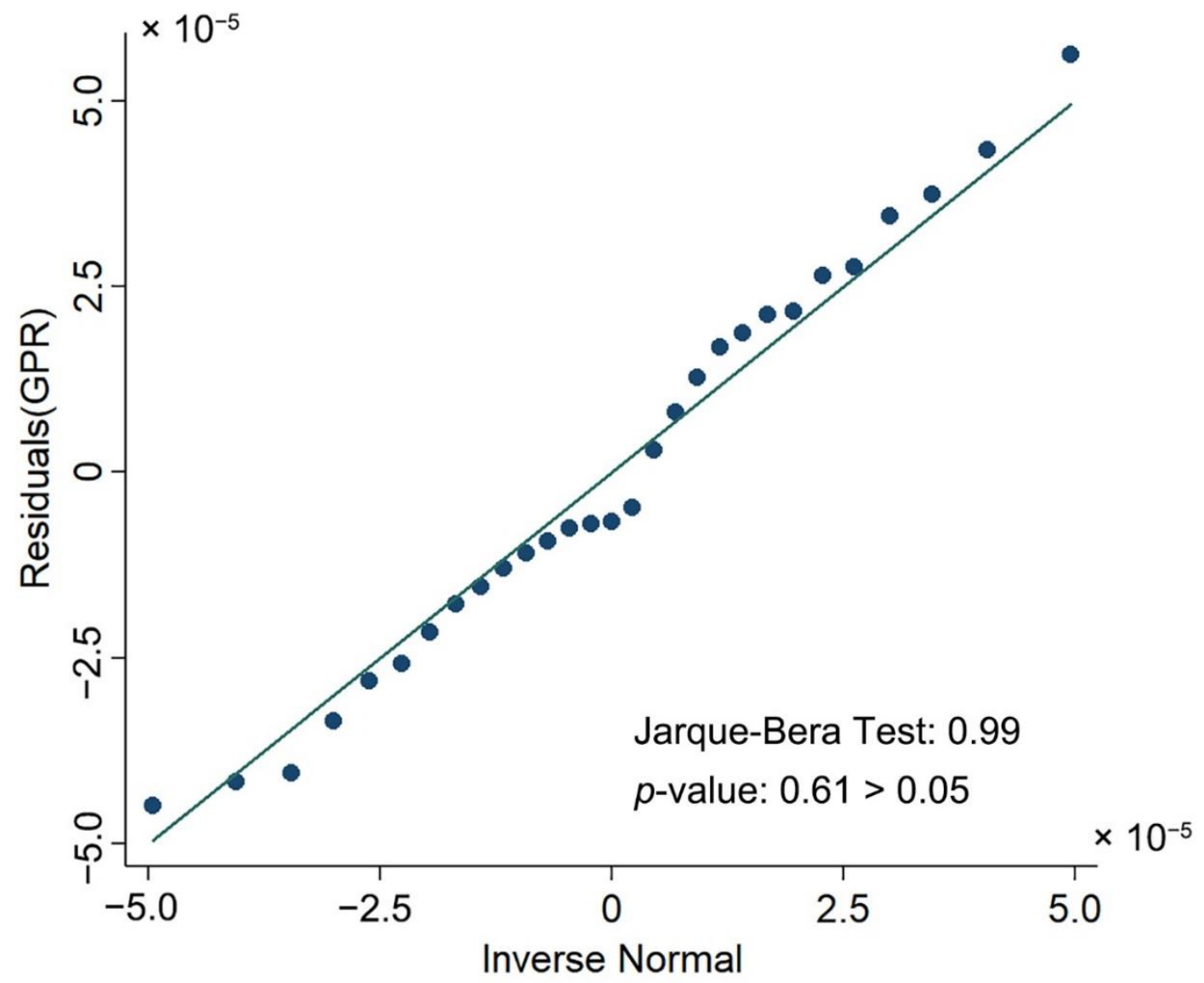

Figure 3. Quantile-quantile plot of the residuals of the Gaussian process regression (GPR). 


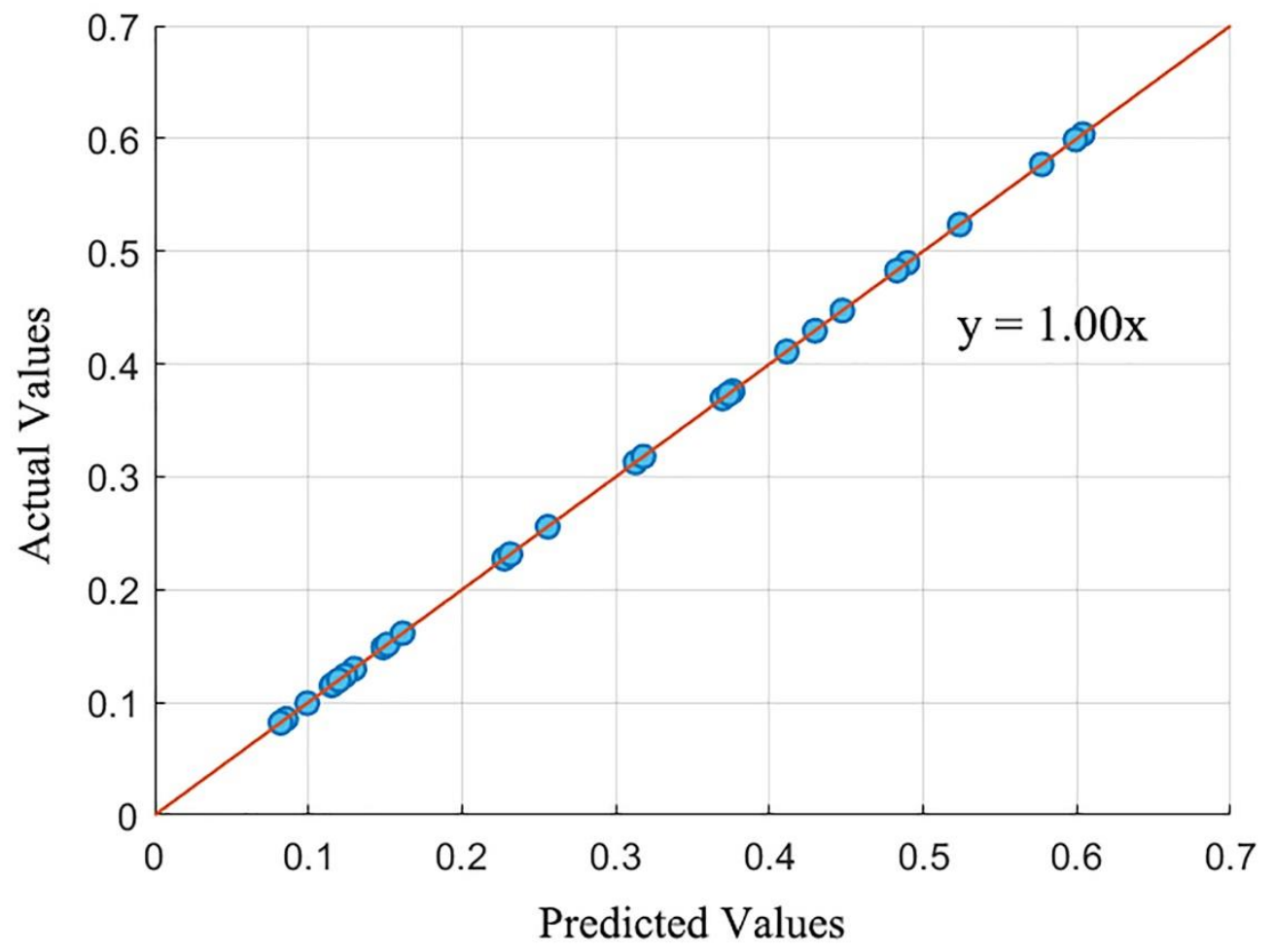

Figure 4. Actual values versus predicted values (new business vitality index).

Table 10 shows that the GPR performs better than the MLR for all three indexes. That $R^{2}$ is 1.000 indicates that the GPR's explanatory power is approximately $100 \%$. That the SSE of the GPR has a very small number that is close to zero means that the residuals of the GPR are very small. We utilize the tolerance of the CV (RMSE) in the energy use issue in this study. According to the ASHRAE Guideline 14, a CV (RMSE) lower than 20\% indicates a good model fit with acceptable predictive capabilities [81]. That the CV (RMSE) of GPR is $0.009 \%$ means that this model explained the relationship between new business vitality and business environment well. The evaluations of the GPR model validate our Hypothesis I. To sum up, the relationship between new business vitality and business environment is not a simple linear relationship, and the GPR model has a better ability to explain the relationship than the MLR model.

Table 10. Evaluations of the MLR model and GPR model.

\begin{tabular}{cccc}
\hline Method & $\mathbf{R}^{2}$ & SSE & CV(RMSE) \\
\hline MLR & 0.478 & 0.437 & $41.828 \%$ \\
GPR & 1.000 & $2.040 \times 10^{-8}$ & $0.009 \%$ \\
\hline
\end{tabular}

\subsubsection{The Comparison between New Business Vitality and per Capita GDP}

In general, GDP per capita should have a strong correlation with business vitality, so we propose Hypothesis III. However, from the ranking of feature importance, GDP per capita is the least important variable. We compared the new business vitality index with per capita GDP (Figure 5) and found that the new business vitality is not exactly proportional to per capita GDP. Cities with low per capita GDP rankings but high new business vitality rankings are Nanning, Haikou, Chengdu, Guiyang, and $X_{i}$ 'an. Cities with high per capita GDP rankings but low new business vitality rankings are Qingdao, Tianjin, Changsha, Shenzhen, and Kunming. The labor quality and the annual number of tourists in the first category of cities are relatively high, which is consistent with the feature importance rankings; the business environment of the latter category of cities is different. For example, Qingdao's other 
business environment rankings are lower than per capita GDP, Changsha's per capita expenditure on science and technology and housing-price-to-income ratio have lower rankings, and Shenzhen's per capita total retail sales of consumer goods and hospital beds rank lower. Based on the previous analysis, Hypothesis III is proved invalid. In short, the relationship between new business vitality and business environment fits the nonlinear Gaussian regression model well, and no one business environment variable (such as per capita GDP) is sufficient to completely explain the new business vitality.

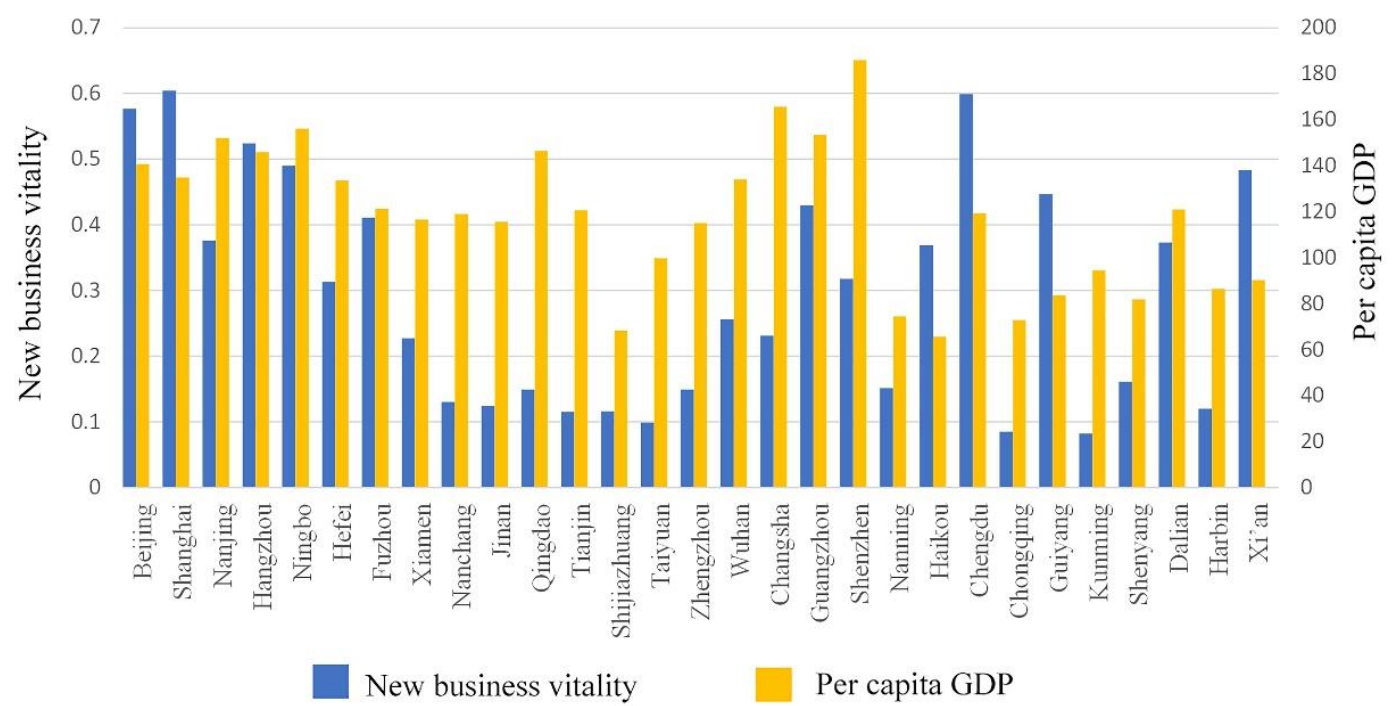

Figure 5. The comparison between new business vitality and per capita GDP.

\section{Discussion}

Industrial upgrading and technological progress are common issues facing the world. At present, the traditional driving force of economic growth is weakening, while new industries and new business forms are rising rapidly. The new economy is becoming an important driving force for global economic growth. China's economy is trying to reduce its dependence on the "infrastructures + real estates" growth model, and the new economy represented by technology, consumption, and services has become the main direction of structural transformation and upgrading. The innovative new economy includes both emerging manufacturing and services, particularly new commercial formats. Therefore, one should promote the smooth connection between financial capital and new commercial formats, actively introduce and cultivate innovative commercial enterprises, and accelerate the transformation from traditional commercial spaces to new commercial spaces. This paper evaluates the vitality of new commercial space and investigates the relationship between commercial vitality and the business environment. This study is not only a new topic of commercial geography, but also has important reference value for urban commerce planning in China and other developing countries.

In the context of rapid technological development, promoting the upgrading of industries and employment is the goal of many cities all over the world. Digital technology is the carrier of industrial upgrading. It is mentioned in "One NYC 2050" that to be competitive in the 21st century requires a population that is digitally literate and prepared for jobs in the burgeoning tech sector. New business formats and vitality based on electronic payments are a practical reflection of industrial upgrading. A good business environment is the necessary condition for industrial upgrading, and the business environment directly affects the new business vitality. A good business environment promotes the progress, transformation, and adaptation to the rapidly developing digital economy of enterprises, stimulates cities' new business vitality, and promotes the upgrading of industries and employment (Figure 6). 


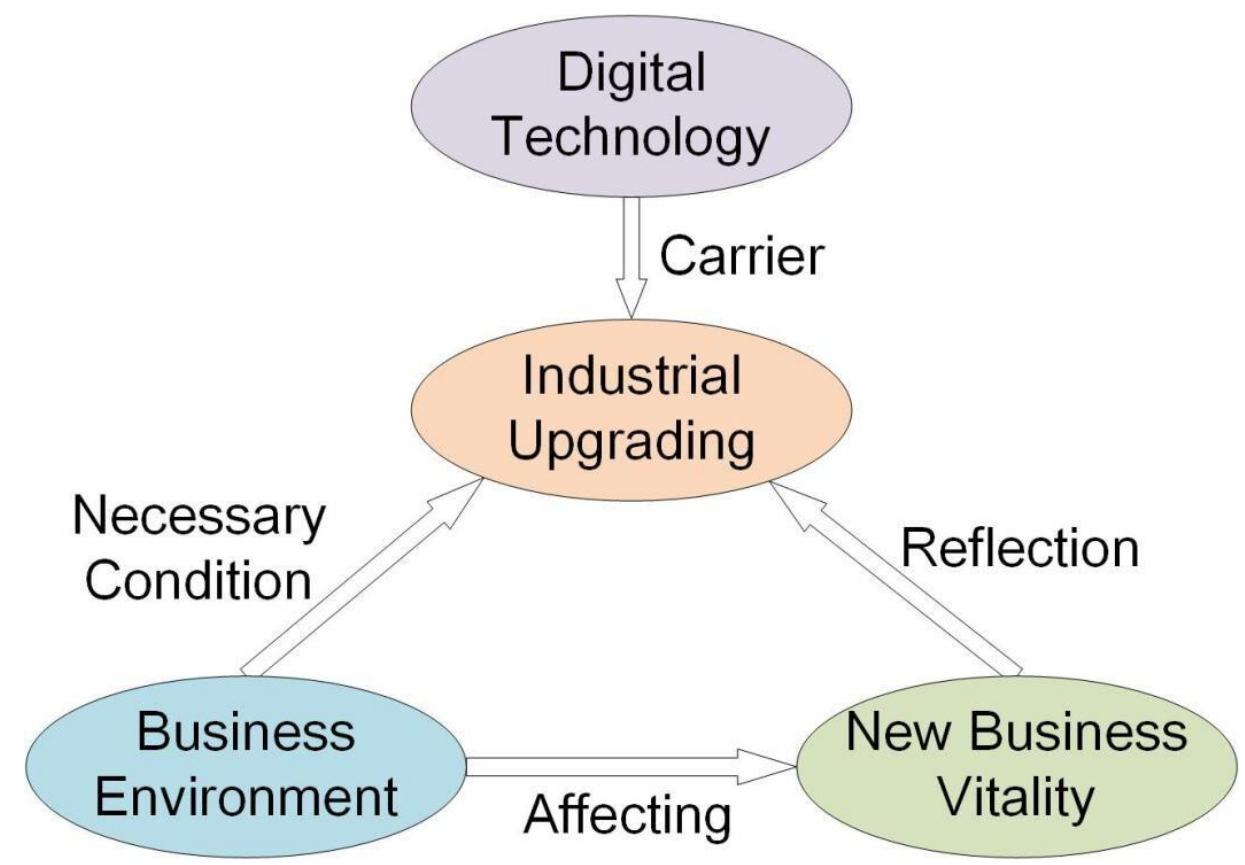

Figure 6. The interactions among business environment, new business vitality, and industrial upgrading.

This paper constructs a new business index system consisting of the following six sub-indexes: the characteristic hotels index, the Starbucks index, the Freshhema index, the concept bookstores index, the smart convenience stores index, and the healthcare and medical examination index. This study expands the research field of traditional commercial space. Previous studies only considered the Atour index, the Starbucks index, and the Freshhema index [82]. Our index system is more refined; more types of new featured businesses (e.g., concept bookstores, smart convenience stores, characteristic hotels, fashionable beverage stores, fresh supermarkets, and healthcare institutions) and their combinations are included. In particular, the new business spaces (e.g., characteristic hotels, Starbucks coffee shops, concept bookstores, smart convenience stores, and Freshhema stores) that involve cultural connotations, such as consumption, experience, values, and lifestyles, have received more attention. Moreover, our index system comprehensively considered the degree of innovation, the degree of fashionableness, the degree of activity, and the degree of intelligence of the studied urban businesses.

We find that the urban social service environment, market environment, and soft environment are the main factors that impact the new business vitality of Chinese cities. This finding is consistent with the actual business environment in Chinese cities. In fact, in recent years, the gaps among the studied cities in the infrastructure environment, ecological environment, and business cost environment have gradually been narrowed. However, the gaps in the social service environment, market environment, and soft environment are expanding. These are also key tasks for the future business environment of Chinese cities. In addition, it should be noted that the impact of the business cost environment and ecological environment may increase. From the perspective of consumers, urban commercial space should not only provide daily necessities and employment opportunities, but also make people feel happy.

In addition to the 10 business environment indicators studied in this article, other impact factors (i.e., financing services, education services, and old-age care services in the social services environment indicators; the cost of starting a business, the cost of contract performance, the cost of property registration, and the tax burden level in the soft environment indicators; PM2.5 concentration and wastewater discharge per unit area in the ecological environment indicators; highway facilities and services, aviation facilities and services, rail facilities and services, and mobile Internet data facilities in the infrastructure environment indicators) could be considered in the regression model. 
It should be pointed out that the construction of any index system is target-oriented and restricted by region. Our empirical research is mainly aimed at Chinese cities, but the new business vitality index constructed here still has certain reference value for cities in other countries or regions. Indeed, it is not easy to build a universal index system under different regulatory, cultural, and other circumstances.

\section{Conclusions and Policy Implications}

From the perspective of the six new commercial formats, the development level of Freshhema stores and smart convenience stores in different cities is obviously different because of the high technical threshold and expensive operation costs involved. As improved models of coffee shops, ordinary hotels, and ordinary bookstores, Starbucks coffee shops, characteristic hotels, and concept bookstores, respectively, have been successively expanded in various cities. There are relatively few differences in the development of healthcare institutions among the studied cities. New businesses require the support of new consumer groups, particularly the fashionable youth group and the highly educated group. Thus, the competition for new consumer groups will become a focus of future urban competition. In fact, measures such as household registration, subsidies, and talent housing are not necessarily able to attract real talents. Creating a livable and business-friendly environment is the core issue that cities need to pay attention to in the future. However, it should be noted that blindly attracting people without limit will often result in the rapid rise of housing prices, which will raise the business costs and, in turn, will curb the inflow of young talents.

Among 29 major cities in Mainland China, the stratification of business innovation is obvious. Shanghai and Beijing are not only the first market for new retail brands, but also have the first-mover advantage in the digitization of physical businesses and business model innovation. It is worth mentioning that in recent years, Chengdu, Hangzhou, Fuzhou, Xi'an, Ningbo, and Guiyang made substantial efforts to grasp the development opportunity of globalization and informatization, relying on advanced commercial infrastructures and relatively open consumption concepts. These cities actively introduced the leading enterprises in business innovation and expanded innovative models. As a result, they increasingly reaped the benefits of undertaking new business incubation, and added vigor to their talent competition strategies.

The rise and development of new commercial forms depend on the innovation and optimization of the business environment. To a large extent, competition today occurs in the institutional environment. A quality business environment featuring legalization, internationalization, and facilitation is an important basis for a city's core competitiveness. The results of feature importance and GPR analysis revealed that the urban soft environment, market environment, and business cost environment are the main factors that impact the new business vitality of Chinese cities. Therefore, to take the lead in urban core competitiveness, one should not only rely on low factor costs to compete, but also focus on optimizing the business environment: increasing support for accounting evaluation, financial services, property transactions, legal services, professional and technical services, and consulting services, and refining industrial services and industrial policy guidance. This approach represents the most lasting and powerful path to success. For example, Atour hotels have created a unique cultural atmosphere through "books + territorial photography", provide intimate services, such as welcoming and delivering guests tea and night snacks, and focus on upgrading the quality of their hotels, which stand out among numerous homogeneous chain hotels and are favored by consumers.

A city's new business vitality is an important reflection of its business environment. The key to measuring the business environment is fairness, convenience, and efficiency. Whether one can achieve the unity of these three goals depends on the degree of activity of the market entities, the degree of enterprise confidence, the degree of empathy of the social groups, and the sense of gain of the city's citizens. Therefore, creating a fair competition environment and stimulating the innovation vitality of market players are key to promoting the sustainable development of new business forms. At the same time, the expansion of new urban business forms should adhere to the idea of giving priority to the well-being of residents, avoid the tendency of purely pursuing the maximization of 
commercial interests, and strive to get rid of the commercial centrism that ignores the convenience of urban planning.

The flattening of information brought by the Internet flattens consumer' cognition and provides new opportunities for business innovation in inland cities. Narrowing the difference between coastal and inland cities in the level of informatization development as soon as possible should be considered a major practical task in promoting China's balanced regional development.

Today's society is moving from the era of industrial economy to the era of digital economy, and artificial intelligence (AI) and technology innovation based on AI are reshaping business and society, which not only brings about a huge transformation of work, wealth, and power, but also has a huge impact on the mode of production and lifestyle of cities [83-85]. For example, AI together with genomics can be used to monitor patient data so as to better understand each patient's physical condition and achieve the goal of precise healthcare. This means that a precise model of healthcare will defeat the traditional model of public healthcare. A variety of new business models contain huge growth potential. Therefore, the mechanisms and spatial effects of various new technologies on the scale, structure, and layout of new business forms and land utilization will become the focus of future research.

Author Contributions: Conceptualization, Y.S.; methodology, D.L.; software, D.L.; validation, D.L. and Y.S.; formal analysis, Y.S.; investigation, Y.S. and D.L.; resources, Y.S.; data curation, D.L.; writing-original draft preparation, Y.S. and D.L.; visualization, D.L.; funding acquisition, Y.S. All authors have read and agreed to the published version of the manuscript.

Funding: This research was funded by the one of key projects for the Shanghai General Land Use Planning Revision (2015(D)-002(F)-11).

Acknowledgments: The authors thank three anonymous reviewers for their valuable comments and suggestions.

Conflicts of Interest: The authors declare no conflict of interest.

\section{References}

1. Guan, C.M.; Cui, G.H. A probe into the new commercial space in Chinese cities and its mechanism. Urban Plan. Forum 2003, 148, 33-36. (In Chinese)

2. Ye, Q.; Chen, N.; Xiang, H.; Tan, Y.T. New Structural Pattern of Urban Commercial Space; Architecture \& Industry Press: Beijing, China, 2015. (In Chinese)

3. Li, F. The digital transformation of business models in the creative industries: A holistic framework and emerging trends. Technovation 2020, 92-93, 102012. [CrossRef]

4. Zhang, Y.; Zhao, S.; Xu, X. Business model innovation: An integrated approach based on elements and functions. Inf. Technol. Manag. 2015, 17, 303-310. [CrossRef]

5. Wang, X.; $\mathrm{Ng}, \mathrm{C} . \mathrm{T}$. New retail versus traditional retail in e-commerce: Channel establishment, price competition, and consumer recognition. Ann. Oper. Res. 2018, 291, 921-937. [CrossRef]

6. Lee, J. Global Commodity Chains and Global Value Chains. Oxford Research Encyclopedia of International Studies. Ed. Available online: http://oxfordre.com/internationalstudies/view/10.1093/acrefore/9780190846626. 001.0001/acrefore-9780190846626-e-201 (accessed on 22 December 2017).

7. Birkin, M.; Clarke, G.; Clarke, M. Retail Location Planning in an Era of Multi-Channel Growth; Routledge: London, UK, 2017.

8. Cai, Y.J.; Lo, C.K.Y. Omni-channel management in the new retailing era: A systematic review and future research agenda. Int. J. Prod. Econ. 2020, 229, 107729. [CrossRef]

9. Liao, S.H.; Yang, L.L. Mobile payment and online to offline retail business models. J. Retail. Consum. Serv. 2020, 57, 102230. [CrossRef]

10. Matsuura, T.; Sunada, M. Welfare Assessment of New Retail Formats: Evidence from Japan's Retail Industry; School of Economics, Osaka Prefecture University: Osaka, Japan, 2010.

11. Chen, C.Q. Competition among Retail Formats. SMU Cox School of Business Research Paper No. 18-28. Available online: http://dx.doi.org/10.2139/ssrn.3218030 (accessed on 22 July 2018).

12. Li, C.Y. On the impact of new business forms on family consumption travel space-A research perspective of "Wal-Martization" of urban consumption. Jiangsu Soc. Sci. 2006, 2006, 232-236. (In Chinese) 
13. Sinha, P.K.; Kar, S.K. Insights into the Growth of New Retail Formats in India. In Retailing in the 21st Century; Krafft, M., Mantrala, M., Eds.; Springer: Berlin/Heidelberg, Germany, 2010; pp. 119-140.

14. Jiang, H.B.; Xu, J.G.; Qi, Y.; Chen, J.T. The quantitative analysis of large scale supermarkets location based on time accessibility and Gasa rules. Geogr. Res. 2010, 29, 1056-1068. (In Chinese)

15. Jhamb, D.; Kiran, R. Emerging retail formats and its attributes: An insight to convenient shopping. Glob. J. Manag. Bus. Res. 2012, 12, 63-71.

16. Shi, Y.; Wu, J.; Wang, S. Spatio-temporal features and the dynamic mechanism of shopping center expansion in Shanghai. Appl. Geogr. 2015, 65, 93-108. [CrossRef]

17. Sharma, R.; Gautam, A. Redefining retail store formats-A South African study. Appl. Financ. Account. 2017, 3, 61-69. [CrossRef]

18. Spilková, J.; Sefrna, L. Uncoordinated new retail development and its impact on land use and soils: A pilot study on the urban fringe of Prague, Czech Republic. Landsc. Urban Plan. 2010, 94, 141-148. [CrossRef]

19. Wang, E.R. Understanding the 'retail revolution' in urban China: A survey of retail formats in Beijing. Serv. Ind. J. 2011, 31, 169-194. [CrossRef]

20. Rotem-Mindali, O. Retail fragmentation vs. urban livability: Applying ecological methods in urban geography research. Appl. Geogr. 2012, 35, 292-299. [CrossRef]

21. Omer, I.; Goldblatt, R. Spatial patterns of retail activity and street network structure in new and traditional Israeli cities. Urban Geogr. 2015. [CrossRef]

22. Beinartz, W.; Wiegand, N.; Imschloss, M. The impact of digital transformation on the retail value chain. Int. J. Res. Mark. 2019, 36, 350-366. [CrossRef]

23. Kärrholm, M.; Nylund, K.; de la Fuente, P.P. Spatial resilience and urban planning: Addressing the interdependence of urban retail areas. Cities 2014, 36, 121-130. [CrossRef]

24. Erkip, F.; Kızılgün, Ö.; Akinci, G.M. Retailers' resilience strategies and their impacts on urban spaces in Turkey. Cities 2014, 36, 112-120. [CrossRef]

25. China Internet Network Information Center. Statistical Report on Internet Development in China. April 2020. Available online: https://cnnic.com.cn/IDR/ReportDownloads/202008/P020200827549953874912.pdf (accessed on 7 December 2020).

26. Beijing Bureau of Statistics, Beijing Investigation Corps of National Bureau of Statistics. Major Areas Gradually Recovered, and Emerging Drivers Grew Rapidly-An Interpretation of the City's Economic Performance in the First Quarter of 2020. 20 April 2020. Available online: http://tj.beijing.gov.cn/zxfbu/ 202004/t20200420_1857059.html (accessed on 7 December 2020).

27. Xiao, Y. Opening 6 New Stores in a Month-From the Acceleration of Freshhema to See the Advancement of New Retail. Economic Daily. 27 April 2020. Available online: http://www.xinhuanet.com/fortune/2020-04/27/ c_1125910693.htm (accessed on 7 December 2020).

28. Li, J. Starbucks Delivery Is Now in Trial Operation. Beijing Youth Daily. 19 September 2018. Available online: http://cnews.chinadaily.com.cn/2018-09/19/content_36943834.htm (accessed on 7 December 2020).

29. Liu, J.; Sun, W.; Hu, W. China Eco-city Construction and Development Report; Social Sciences Academic Press: Beijing, China, 2018. (In Chinese)

30. Liu, L. A sustainability index with attention to environmental justice for eco-city classification and assessment. Ecol. Indic. 2018, 85, 904-914. [CrossRef]

31. Zhang, J. Review of related studies on eco-city theory. Asian Agric. Res. 2019, 11, 28-33.

32. Beatley, T. Green Urbanism: Learning from European Cities; Island Press: Washington, DC, USA, 2000.

33. Birch, E.L.; Wachter, S.M. Growing Greener Cities: Urban Sustainability in the Twenty Century; University of Pennsylvania Press: Philadelphia, PA, USA, 2008.

34. Wu, Z.; Chen, R.; Meadows, M.E.; Sengupta, D.; Xu, D. Changing urban green spaces in Shanghai: Trends, drivers and policy implications. Land Use Policy 2019, 87, 104080. [CrossRef]

35. Wang, J.; Su, M.; Chen, B.; Chen, S.; Liang, C. A comparative study of Beijing and three global cities: A perspective on urban livability. Front. Earth Sci. 2010, 5, 323-329. [CrossRef]

36. Marsal-Llacuna, M.L.; Colomer-Llinàs, J.; Meléndez-Frigola, J. Lessons in urban monitoring taken from sustainable and livable cities to better address the Smart Cities initiative. Technol. Forecast. Soc. Chang. 2015, 90, 611-622. [CrossRef]

37. Jenks, M.; Burton, E.; Williams, K. The Compact City: A Sustainable Urban Form? Spon Press: London, UK, 1996. 
38. Lee, J.; Kurisu, K.; An, K.; Hanaki, K. Development of the compact city index and its application to Japanese cities. Urban Stud. 2015, 52, 1054-1070. [CrossRef]

39. Ahvenniemi, H.; Huovila, A.; Pinto-Seppä, I.; Airaksinen, M. What are the differences between sustainable and smart cities? Cities 2017, 60, 234-245. [CrossRef]

40. Meerow, S.; Newell, J.P.; Stults, M. Defining urban resilience: A review. Landsc. Urban Plan. 2017, 147, $38-49$. [CrossRef]

41. Fischer, M.M.; Diez, J.R.; Snickars, E. Metropolitan Innovation Systems: Theory and Evidence from Three Metropolitan Regions in Europe; Springer Science \& Business Media: Berlin, Germany, 2001.

42. Shi, Y.; Bu, H. Evaluation index system and comparative analysis of innovation-oriented cities. China Sci. Technol. Forum 2008, 24, 22-26. (In Chinese)

43. Beaverstock, J.V.; Smith, R.G.; Taylor, P.J.; Walker, D.R.F.; Lorimer, H. Globalization and world cities: Some measurement methodologies. Appl. Geogr. 2000, 20, 43-63. [CrossRef]

44. Zhou, Z. Edit in Chief. Global Cities Development Index 2019; Shanghai People's Publishing House: Shanghai, China, 2019. (In Chinese)

45. Jin, Y.J. Study on urban economic vitality index in China. Sci. Geogr. Sin. 2007, 27, 9-16. (In Chinese)

46. Sustainable Cities Research Group, Institute of Urban Environment, Chinese Academy of Sciences. China Sustainable Urban Development Report: Compact Cities; China Environmental Science Press: Beijing, China, 2013. (In Chinese)

47. Ni, P.; Hou, Q.; Jiang, M.; Wang, C. Annual Report on Urban Competitiveness (No.3); Social Sciences Academic Press: Beijing, China, 2005. (In Chinese)

48. Wang, R.J.; Li, J.P.; Li, M.R.; Shi, X.Y.; Huang, M.X. Report on City Innovation Competitiveness in China. Social Science Academic Press: Beijing, China, 2018. (In Chinese)

49. Clarke, G.; Li, Y.; Xu, L.C. Business environment, economic agglomeration and job creation around the world. Appl. Econ. 2016, 48, 3088-3103. [CrossRef]

50. Cepel, M.; Stasiukynas, A.; Kotaskova, A.; Dvorsky, J. Business environment quality index in the sme segment. J. Compet. 2018, 10, 21-40. [CrossRef]

51. Borojo, D.G.; Yushi, J. The impacts of institutional quality and business environment on Chinese foreign direct investment flow to African countries. Econ. Res. -Ekon. Istraživanja 2019, 33, 26-45. [CrossRef]

52. Nam, V.H.; Bao Tram, H. Business environment and innovation persistence: The case of small- and medium-sized enterprises in Vietnam. Econ. Innov. New Technol. 2019. [CrossRef]

53. Gogokhia, T.; Berulava, G. Business environment reforms, innovation and firm productivity in transition economies. Eurasian Bus. Rev. 2020. [CrossRef]

54. Hwang, C.L.; Yoon, K. Multiple Attribute Decision Making: Methods and Applications; Springer-Verlag: New York, NY, USA, 1981. [CrossRef]

55. Bayram, B.Ç. Evaluation of forest products trade economic contribution by entropy-TOPSIS: Case study of Turkey. BioResources 2020, 15, 1419-1429. [CrossRef]

56. Chang, C.H.; Lin, J.J.; Lin, J.H.; Chiang, M.C. Domestic open-end equity mutual fund performance evaluation using extended TOPSIS method with different distance approaches. Expert Syst. Appl. 2010, 37, 4642-4649. [CrossRef]

57. Aalami, H.A.; Moghaddam, M.P.; Yousefi, G.R. Modeling and prioritizing demand response programs in power markets. Electr. Power Syst. Res. 2010, 80, 426-435. [CrossRef]

58. Chamodrakas, I.; Martakos, D. A utility-based fuzzy TOPSIS method for energy efficient network selection in heterogeneous wireless networks. Appl. Soft Comput. 2011, 11, 3734-3743. [CrossRef]

59. Lei, X.; Robin, Q.; Liu, Y. Evaluation of regional land use performance based on entropy TOPSIS model and diagnosis of its obstacle factors. Trans. Chin. Soc. Agric. Eng. 2016, 32, 243-253. (In Chinese)

60. Lin, H.; Pan, T.; Chen, S. Comprehensive evaluation of urban air quality using the relative entropy theory and improved TOPSIS method. Air Qual. Atmos. Health 2020. [CrossRef]

61. Behzadian, M.; Otaghsara, S.K.; Yazdani, M.; Ignatius, J. A state-of the-art survey of TOPSIS applications. Expert Syst. Appl. 2012, 39, 13051-13069. [CrossRef]

62. Wu, L.Y.; Yang, Y.Z. TOPSIS Method for green vendor selection in coal industry group. In Proceedings of the Seventh International Conference on Machine Learning and Cybernetics 2008, Kunming, China, 12-15 July 2008; pp. 1721-1725. 
63. Robnik-Sikonja, M.; Kononenko, I. An adaptation of Relief for attribute estimation in regression. In Proceedings of the Fourteenth International Conference on Machine Learning, Nashville, TN, USA, 8-12 July 1997; Morgan Kaufmann Publishers Inc.: Burlington, NJ, USA, 1997; Volume 5, pp. $296-304$.

64. Robnik-Šikonja, M.; Kononenko, I. Theoretical and Empirical Analysis of ReliefF and RReliefF. Mach. Learn. 2003, 53, 23-69. [CrossRef]

65. Rasmussen, C.E.; Williams, C.K. Gaussian Processes for Machine Learning; The MIT Press: Cambridge, MA, USA, 2006.

66. Alizadeh, F.; Roushangar, K. Investigating effect of socio-economic and climatic variables in urban water consumption prediction via Gaussian process regression approach. Water Supply 2018, 18, 84-93.

67. Lubbe, F.; Maritz, J.; Harms, T. Evaluating the potential of Gaussian process regression for solar radiation forecasting: A case study. Energies 2020, 13, 5509. [CrossRef]

68. Kozlowski, M. Barnes and Noble to Open New Concept Store that Focuses on Books. Available online: https:/goodereader.com/blog/bookselling/barnes-and-noble-to-open-new-concept-storethat-focuses-on-books (accessed on 9 October 2018).

69. Wang, X.L. New bookstore business model and sustainable development. China Publ. J. 2018, 2018 , 58-61. (In Chinese)

70. Jennings, R. Why Unmanned Stores are about to Take Off in China's Retail Market? Editor's Pick. Available online: https://www.forbes.com/sites/ralphjennings/2018/05/14/why-china-is-uniquely-wellplaced-to-develop-fully-automated-retail-stores/\#19e0923a2aea (accessed on 14 May 2018).

71. Wang, X.; Jia, Z.H. Cultural features positioning and design expression of boutique hotels. Huazhong Archit. 2018, 30, 24-27. (In Chinese)

72. TravelMaestro. 9 Characteristics of Boutique Hotels. Available online: https:/www.covingtontravel.com/ 2016/02/9-characteristics-of-boutique-hotels/ (accessed on 26 February 2016).

73. Wikipedia. Boutique Hotel. Available online: https://en.wikipedia.org/wiki/Boutique_hotel (accessed on 12 February 2019).

74. Wang, F.X.; Chen, Y.J.; Xia, S. Study on the business model of fresh supermarket under the background of "new retail"-Based on the comparison of multiple cases. J. Commer. Econ. 2018, 2018, 35-37. (In Chinese)

75. Cherulinam, F. Business Environment: Text and Cases, 21st ed.; Himalaya Publishing House: Mumbai, India, 2012.

76. Hilton, R.W.; Platt, D.E. Managerial Accounting: Creating Value in a Dynamic Business Environment, 10th ed.; McGraw-Hill Education: New York, NY, USA, 2013.

77. Miller, D. Relating Porter's business strategies to environment and structure: Analysis and performance implications. Acad. Manag. J. 2017, 31. [CrossRef]

78. World Bank. Doing Business 2018: Reforming to Create Jobs; World Bank: Washington, DC, USA, 2018. Available online: https://openknowledge.worldbank.org/handle/10986/28608 (accessed on 15 October 2019).

79. Institute of Guangdong-Hong Kong-Macao Greater Bay Area. China Urban Business Environment Reportin 2017. Available online: https://www.docin.com/p-2064159393.html (accessed on 13 October 2019). (In Chinese)

80. Mang, S.; $\mathrm{Wu}, \mathrm{X}$. Comparative interpretation and enlightenment of the evaluation index system of business environment at home and abroad. Stat. Consult. 2018, 25, 27-30. (In Chinese)

81. O' Donovan, A.; O' Sullivan, P.D.; Murphy, M.D. Predicting air temperatures in a naturally ventilated nearly zero energy building: Calibration, validation, analysis and approaches. Appl. Energy 2019, 250, 991-1010. [CrossRef]

82. China Real Estate Chamber of Commerce, RET Ruiyade. Research Report on New Business Cities in China in 2018. Available online: http://biz.ifeng.com/a/20180828/45142400_0.shtml (accessed on 28 August 2018). (In Chinese)

83. Goldsby, T.J.; Zinn, W. Technology innovation and new business models: Can logistics and supply chain research accelerate the evolution? J. Bus. Logist. 2016, 37, 80-81. [CrossRef] 
84. Taneja, H.; Maney, K. Unscaled: How AI and a New Generation of Upstarts Are Creating the Economy of the Future; Hachette Book Group: New York, NY, USA, 2018.

85. Valter, P.; Lindgren, P.; Prasad, R. Advanced business model innovation supported by artificial intelligence and deep learning. Wirel. Pers. Commun. 2018, 100, 97-111. [CrossRef]

Publisher's Note: MDPI stays neutral with regard to jurisdictional claims in published maps and institutional affiliations.

(C) 2020 by the authors. Licensee MDPI, Basel, Switzerland. This article is an open access article distributed under the terms and conditions of the Creative Commons Attribution (CC BY) license (http://creativecommons.org/licenses/by/4.0/). 